\title{
The pedagogy and principles of teaching therapeutic practice with children and young people.
}

BOLGER, J.

2019

This article has been accepted for publication in Journal of Teaching in Social Work, published by Taylor \& Francis. 


\title{
The Pedagogy and Principles of Teaching Therapeutic Practice with Children \& Young People
}

Janine Bolger

Head of Social Work/Associate Head of School of Applied Social Studies, Robert Gordon University, Aberdeen, United Kingdom

\begin{abstract}
Technical/rational approaches which suggest that systematically produced, generalised and scientific knowledge are the most solid foundations for practice present significant challenges for the social work profession, in which the decisions faced often are not technical but moral, requiring the application of ethically-based and intuitive skills. Meanwhile the command, control and measurement of outcomes in social work practice also present significant conundrums for the delivery of relational person centred social work and social care. With a focus too often on efficiency rather than effectiveness, this managerialistic approach fails to acknowledge the complexity inherent in the act of caring. In this context and framework, teaching therapeutic practice with children draws a balance between traditional systematic teaching methods and use of creative media including art, play and music. This article outlines the positive contribution to professional social work practice that the teaching of therapeutic approaches to childcare can make.
\end{abstract}

\section{The incorporation of therapeutic practice into the curriculum}

Social workers come in contact with individuals, families and even communities when they are overwhelmed by "dysphoric emotions and distress" when the balance in their lives is upset and when they are encountering issues or difficulties that have a negative impact of "their sense of self and experiences." (Megele 2015. P1). 
Evidence suggests that the catalyst of change for many service users is the opportunity to form warm, empathic and productive relationships with a worker who is interested and cares for them (Bellefeuille, Jamieson \& Ricks 2012; Jackson, Ajayi and Quigley 2005). The building of such a positive human relationship is at the very core of personal recovery, and it is the sense of a worker being in the present and attuned that transforms technical tasks of caring into nurturing developmental opportunities.

At the heart of these interventions lie relationship-based practices which enable and empower individuals, families and communities. The purpose in facilitating student's learning around therapeutic practice is to encourage them to look beyond the current emphasis, in practice, on technical rational approaches that eliminate risk through information gathering and formulaic models of decision making to the more traditional, and historical methods of social work.

In short, therapeutic practice is a curative approach serving or performing to maintain an individual's health (Collins 1989). Therapeutic interventions offer a sense of universality and a cathartic experience (Yalom 1986). Moreover, such approaches relieve pain through the freeing of 'stuck' points of development via the repair and reconstruction of the inner world which can only take place through the provision of a secure base (Trieschman, Whittaker and Brendtro 1969). Containment (Bion 1962) and holding (Winnicott 1964) will help repair and reconstruct the child's inner world. This process inevitably involves the building of relationships and affirmation which is at the core of human experience.

The idea of 'holding' was first used to describe the provision of an optimal environment for 'good enough' parenting, beginning with an almost complete adaptation by primary carers to their infant's needs (Winnicott 1953). The concept supposes that over time the carer increases the amount of time between the child's emotional expression of need and their response as caregiver. Through this process, children discover that they can survive the process of feeling overwhelmed by their own needs until their caregiver demonstrates capacity to meet those demands. 
In conjunction with the notion of holding, the theory of containment (Bion 1962) explains the way in which individuals are supported to use thinking to manage their experiences and emotions (Emond, Steckley and Roesche-Marsh 2016). The child's attachment figure typically provides the first experiences of containment in response to the infant's experiences of pain, discomfort and even fear. Their active soothing of the infant, through feeding, changing the nappy, rocking, and so on, accompanied by the verbal identification or confirmation of emotions and experiences helps children to learn how to use thinking to manage their experiences (I bid).

The premise of therapeutic practice is that through engagement and connectedness relational working occurs (Bellefeuille, Jamieson \& Ricks 2012). Working therapeutically with children and young people allows for the opportunity to build relationships within the context of a secure base. In developing the quality of relationship we enhance the "hopefulness to remain curious and open to new experiences, and the capacity to see connections and discover meanings" (Smith and Smith 2008. P71). The building of positive human relationships is at the very core of recovery.

Good relationship-based practice requires effective use of self. This fact relies on the worker's knowledge of self and the underlying assumptions held about relationships and aspects (cultural, emotional, psychological and political) that shape our identities (Megele 2015). Such knowledge is the foundation for growth and for the enhancement of professional identity and practice. These approaches generate a relational dialogue that is empowering to service users so that "you and I happening together makes us immediately different than we usually are" (Gendlin 1998 in Megele 2015 Pg 182).

The Promotion of Therapeutic Approaches as Tools for Practice

Historically the geographical and emotional space reserved for therapeutic work was provided in specialised residential environments where a therapeutic community approach is usually applied in a residential setting and where educational provision is often incorporated. Currently, services 
for children and young people, requiring therapeutic interventions, are provided through health care, education, social welfare or criminal justice systems, and sometimes at home, within the community or in group care settings (Fulcher and Ainsworth 2006). For many of the young people who come to the attention of social services, trauma, abuse and neglect sadly are a reality of life. Without the resolution of trauma, feelings of fear, helplessness and a loss of control are likely repeated. The individual's vulnerability is increased, and behaviours and relationships are impacted. When providing good enough support for a child, whether living at home, with friends or relatives, in foster care or in group care, it is hoped that recovery can be part of that reality (Tomlinson 2004).

Instability or disruption in early life experiences can result in major problems for children and young people in trusting others and, therefore, in the potential for attaching not only to family but to subsequent care givers. Faulty attachment brings about specific kinds of problems including difficulty in managing emotions, lack of trust, and a need to be in control. Children who regularly experience uncontained emotions can be highly reactive, will experience difficulty in recognising their need for (and others' attempts to give) support, may struggle to manage normative rhythms and routines, and will generally be unable to reflect on their own behaviour and its impact on others (Emond, Steckley and Roesch-Marsh 2016). Containing another person while helping them acquire the skills to self-contain is no easy or quick task; however, the social and emotional benefits of a good containing relationship and environment allows individuals to feel understood, safe and respected. Containment involves absorption through calm receptiveness and active cognitive processing (Bion 1962) culminating in empathetic acknowledgement. Even though children with attachment issues experience difficulties in building and maintaining relationships, attachment disorders can be repaired. Trust and security come with time, consistency, dependability and repetition. 


\section{The Purpose of Promoting Relational Working}

The core component of therapeutic practice is the ability to respond to the emotional needs of individuals and groups, "to their impulse for emotional development, and to the difficulties they experience in forming or maintaining relationships" (Sudberry, 2010. P150). Emotional development and the management of emotions are interrupted by experiences of trauma, abuse and neglect. The key to therapeutic practice is to discover ways to provide opportunities for children to (re)discover the ability to use thinking to manage both their experiences and emotions, that is, self-regulation and containment (Bion 1962).

Such helping relationships are complex and do not always sit well within dominant notions of professionalism (Biestek 1961). It is vital that social work students and graduates reflect on and, if necessary, challenge the purpose of their role within an agency when working with children and young people. They might be required, by their employer, to take on a role that comes, for example, from care management and is likely to focus on monitoring of behaviour rather than on supporting service users to explore and to learn (Smith and Smith 2008). The question of who should do what in a helping process is central to the practice of social pedagogy (Storo 2013). Students require support to understand phenomena at different levels of abstraction in the way in which they translate theory into practice. Storo (2013) suggests that practice can be understood as the realisation of such thoughts. Humanistic values pervade social pedagogic practice and translate into a sense of equality between the worker, service user(s) and community. Inter-disciplinary theories from the social sciences, social work, education and allied health studies underpin holistic practice, supporting the balance between the professional, the personal and the practical. Social Pedagogy counteracts more risk-aversive practices and is based on partnership through a commitment to relationship building, problem solving and social change.

Key to therapeutic endeavour is how the worker engages with the inner child. "This inner world consists of a mixture of the conscious and the 
less-than-conscious: thoughts and feelings, fears and imaginings, understandings and misunderstandings, dreams and nightmares, images of people and places and assumptions about their meaning or importance" (Ward and McMahon, 1998 P11-12). Experiential approaches that facilitate engagement of individuals in activity around self-exploration, communication and developmental reparation encourage involvement with the inner world via the therapeutic process (Malchiodi and Crenshaw 2014).

\section{Facilitating teaching around Therapeutic Practice with Children}

The purpose of teaching around therapeutic practice with children is to promote awareness of the significance and potential of therapeutic relationships with children who are in receipt of social services. Students can be supported to consider the processes that facilitate and hinder the development of therapeutic milieu and encouraged them to become familiar with a range of therapeutic interventions. With a focus on philosophical and ethical issues students can be introduced to the origins and concepts that underpin therapeutic practice. This process begins with learning about the significance of early experiences. Teaching should consider a range of prerequisite knowledge and skills for working with families and groups and addresses an assortment of practice issues. Classes can be structured to enhance knowledge, skills and application, and as such can be divided between interactive taught session, skills session and project work.

Practice skills sessions encompass working with paint and clay, making masks, puppets, musical instruments, story-telling, singing and using therapeutic photography as tools for supporting children and young people to express themselves. These sessions integrate exercises around the application of the specific skill to practice situations.

Project work, which has been a core element of social pedagogical education in Scandanavia since the 1980's, provides an opportunity to consolidate and apply knowledge and skills in relation to 'real life' 
situations via a case study approach and to present a relevant programme of intervention to service users and social work professionals.

\section{The Use of Creative Media in I nterventions}

The use of creative arts provides a combination of visual, tactile, auditory, olfactory and kinaesthetic sensory experiences. Sensory based experiences in early childhood can reinforce secure attachment and connections with others. Emotional self-regulation (the external and internal processes responsible for monitoring, reviewing and modifying emotional reactions) along with empathy also can be encouraged through the use of creative arts (Perry in Malchiodi and Crenshaw 2014). Malchiodi (2008) suggested that interventions based on the creative arts are normalising in that they reinforce cross-cultural experiences relating to wellness practices, which might take the form of singing, story-telling, creating images and such while offering opportunity to create comprehensive links between theory and practice. According to Perry (2008), such actions are effective in changing neural systems involved in stress responses and promoting secure attachment.

\section{Preparing Students for Practice: Organisational, Practice and Cultural Contexts}

When preparing students to integrate therapeutic ideas and concepts with practice, it is important that awareness of organisational, practice, and cultural contexts be highlighted throughout the teaching programme. Practice contexts are influenced by the current socio-political climate and local organisational culture (Lishman 2012). Fulcher and Ainsworth (2006) commented on the lack of attention paid to the impact of the organisational context other than to acknowledge its existence. They suggested that there is a "tendency of organisational management to perceive the organisation as benevolent and supportive, allowing little room for a consideration of how this context impacts harmfully on the 
primary responsibilities of the care staff and what might be done to bring a greater balance between these two important demands" (Fulcher and Ainsworth, 2006 P89). In short, too often the needs of the organisation can detract from the nature of the individualised primary care provided. According to Maier (1979) the quality of care given has a direct correlation to the manner in which a worker is supported by the organisation (cited in Fulcher et al, 2006). Opportunities to respond to the needs of traumatised children in creative and innovative ways are usually indicative of 'thinking' cultures.

To develop and maintain a trauma-sensitive culture, students are taught that flexibility and creativity should be encouraged, whereas rigidity and reactivity should be discouraged. Creativity can be one of the best defences against systems that are stagnant or punitive. The creation of a democratic environment, in which staff are supported to try new things, offer suggestions, and be involved in decision making within the context of the shared values of their organisation, is encouraged because it allows space for creativity. It is recognised that strict hierarchical systems encourage the devolving upward of responsibility while handing down blame. By eradicating blame and, instead, engaging in shared problem solving, staff teams can discover a wider range of voices from which solutions can emerge.

The current emphasis in social work on seeking technical/rational solutions is reminiscent of the concerns for classification and order as demonstrated by the English social reformers of the $19^{\text {th }}$ century. Whereas "the wider social context of behaviour, the impact of structural factors such as poverty and community fragmentation, have become marginalised in social work practice" (Smith and Whyte 2008 P23). Furthermore, the trend towards managerialist approaches in social work practice has left many workers feeling that the skills they are required to use in practice are more instrumental and procedural than they would wish and have rendered irrelevant much of their training (Hatton 2015). 
Teaching content encourages students to identify opportunities for examining and contributing to the transformation of dynamics within the agency. This will inevitably involve workers, children, families and management at all levels in order to achieve a positive culture through the creation of a unified organisation in which all members participate in making decisions and accept responsibility for the safety and well-being of others. Such an outcome requires cooperation and congruence wherein workers mutually engage in a constructive manner and share an understanding of both their own circumstances and the task to be carried out with service users. It is acknowledged that only when this phenomenon occurs can the emotional and development needs of traumatised children and young people be met and the resulting healing will take place.

\section{Are Therapeutic Approaches to Practice Always the Answer?}

Adopting approaches that are underpinned by psychodynamic models of practice can be open to criticism for individualising problems and pathologising the individual. Such approaches might also be disapproved of for a failure to consider the contexts of poverty and oppression with which many service users face. Other aspects of a service users' reality, such as racism and gender stereotyping, could also be disregarded (Ward and McMahon, 1998). However, it might be argued that the reintroduction of psychodynamic interventions into social work can introduce both practical and developmental dimensions back into practice.

Further critique has been extended towards psychodynamic models for being too introspective (Ward and McMahon, 1998) but "effective psychosocial and relationship based practice in social work and social care is a deeply engaged experience that is systematic in thinking and personcentred yet persuasively directive in practice" (Megele 2015. P6).

Psychodynamic ways of working present a real challenge to areas of social work practice which might be more likely to champion technical rational 
approaches to case management. The rise of managerialism in welfare and education systems has resulted in a decline in the autonomy and discretion of front line workers and a move towards routinized and prescribed activity. A trend towards "targeting, achieving predefined outcomes, and a heightened concern with accreditation and 'hard products', has had a fundamental impact." (Smith and Smith 2008. P136). Emphasis on structured activity can damage the quality of therapeutic work with its sole emphasis on outcome rather than process.

\section{Conclusion}

Therapeutic views of social work which focus on wellbeing, fulfilment and personal growth through mutual interaction leading to empowerment, enable the individual or group to rise above suffering and disadvantage (Payne, 2006) and to challenge the more technical rational approaches to case management. The attempt to modify the perception and practice of therapeutic approaches through the integration of transformational and social order views results in a more modern application of therapeutic practice in social work education as a core to daily practice. 


\section{References}

- BELLEFEUILLE, G., JAMIESON, D. and RICKS, F., 2012. $2^{\text {nd }}$ ed. Standing on the precipice. Alberta: MacEwan.

- BIESTEK, F., 1961. The Casework Relationship. London: Unwin University Books.

- BION, W.R. 1962. Learning from Experience. London: Karnac.

- COLLINS., 1989. Concise Dictionary. Glasgow: William Collins \& Sons.

- EMOND, R., STECKLEY, L. and ROESCH-MARSH, A., 2016. A Guide to Therapeutic Child Care. London: J essica Kingsley.

- FULCHER, L.C. and AINSWORTH, F., 2006. Group Care Practice with Children and Young People Revisited. New York: The Haworth Press.

- HATTON, K., 2015. $2^{\text {nd }}$ edition. New Directions in Social Work Practice. London: Sage.

- JACKSON, S., AJAYI, S. and QUIGLEY, M., 2005. Going to university from care: Final report of the By Degrees project. London: Institute of Education.

- LISHMAN, J. (Eds)., 2012. Social Work Education and Training. London: Jessica Kingsley.

- MAIER, H. W., 1979. 'The core of care: essential ingredients for the development of children at home and away from home', Child Care Quarterly, vol 8, no 4 pp 161-73.

- MALCHIODI, C. and CRENSHAW, D. (Eds)., 2014. Creative Arts and Play Therapy for Attachment Problems. New York: Guilford Press.

- MEGELE, C., 2015. Psychosocial and Relationship-based practice. Northwich: Critical Publishing.

- PAYNE, M., 2006. What is Professional Social Work? Revised $2^{\text {nd }}$ Edition. Bristol: Policy Press/BASW.

- PERRY, B. Foreward. In C.A,Malchiodi (Ed.), Creative Interventions with Traumatised Children (pp. ix-xi). New York: Guilford Press.

- SMITH, H AND SMITH, M. 2008. The Art of Helping Others. London: Jessica Kingsley. 
- SMITH, M AND WHYTE, B. 2008. Social Education and Social Pedagogy: reclaiming a Scottish Tradition in Social Work. European J ournal of Social Work, 11:1, 15-28.

- STORO, J., 2013. Practical Social Pedagogy: Theories, values and tools for working with children and young people. Bristol: The Policy Press.

- SUDBERRY, J., 2010. Key Features of Therapeutic Social Work: The Use of Relationship. J ournal of Social Work Practice: Psychotherapeutic Approaches in Health, Welfare and the Community, 16:2, 149-162.

- TOMLINSON, P. 2004. Therapeutic Approaches in work with Traumatised children and Young People. London: Jessica Kingsley.

- TRIESCHMAN, A., WHITTAKER, J., and BRENDTRO, L. 1969. The Other 23 Hours. New York: Aldine.

- WARD, A., and MCMAHON, L., (Eds). 1998. Intuition is not Enough. Matching learning with Practice in Therapeutic Child Care. London: Routledge.

- WINNICOTT, D. 1964. The Child, the Family and the Outside World. Harmondsorth: Penguin.

- YALOM, I. 1986. The Theory and Practice of Group Psychotherapy. New York: Basic Books. 